\title{
A Comparative Study of Chinese and American Engineering Education Professional Certification Standards
}

\author{
Fenping Wang ${ }^{1, a, *}$ \\ ${ }^{1}$ School of Science, Jinling Institute of Technology Nanjing Jiangsu China \\ ${ }^{a}$ wpp@jit.edu.cn \\ *corresponding author
}

\begin{abstract}
The indicators of engineering education accreditation standards in China and the United States are compared. On the whole, there is no substantive difference in the accreditation standards of engineering education between China and the United States, including students, professional education goals, and student achievement (performance). continuous improvement, curriculum, faculty and staff, teaching equipment, related institutions and leadership. The Chinese certification standards specifically and in detail explain the specific practices and approaches of each level of indicators. The US certification standards are relatively general. In addition to the general engineering education certification standards, the every United States certification standards version include professional certification standards, while the Chinese certification standards only include professional certification standards in 2011version.
\end{abstract}

Keywords: applied science and engineering major, accreditation standard, international comparison

\section{INTRODUCTION}

The View of The Board on International Comparative education Study in Education,: understand others and educate yourself,This is also the main motivation of this study. The United States is the most industrialized country, and until 2007 it had the largest number of science and engineering PHDS. As the most developed country in science and technology and economy, the United States has a long history of engineering education certification. In 2007 ,China overtook the United States as the country with the largest number of PHDS in science and engineering. According to the "China engineering education quality report" released by the higher education evaluation center of the ministry of china education in 2016, the number of students, The number of students and graduates of engineering majors in Chinese universities and colleges ranks come to top in the world, which is 3-5 times higher than that of Russia and the United States. The rapid development of China's economy needs more and more application-oriented talents, and application-oriented universities take cultivating application-oriented talents as the main goal. In March 2014, the ministry of education of China made it clear that more than 600 of the 1,200 regular undergraduate institutions of higher learning in China will gradually transform into universities based on applied technology, with the transformed universities accounting for exactly $50 \%$ of the total number of universities. Applied undergraduate focuses on the word application, engineering major is the main body of applied majors. Looked from the overall employment situation in recent years, relatively higher employment for graduates in engineering, put forward "made in China 2025", although the engineering professional graduate employment rate has been high,but There is a structural surplus and shortage of engineering graduates, college level and graduate level engineering graduate supply cannot completely meet the demand of enterprise and industry, at the same time in terms of the connotation of the quality of talent training and the support elements, the last kilometer of talent need to be truly fall to the ground. There is room for improvement in talent cultivation in the ten key areas of emerging industries and manufacturing industry. The problems in volume and structure of talent, such as the precise matching between regional engineering talent scale and industrial scale, need to be solved as soon as possible. This is also one of the main reasons for china to start the national professional certification. The professional certification of engineering education is an internationally accepted system, The standard is a kind of qualification evaluation oriented by training objectives and graduation requirements. The certification of engineering education requires the establishment of professional curriculum system, the allocation of teachers, and the allocation of school conditions, all of which focus on the core task of students' graduation ability, and emphasize the establishment of professional continuous improvement mechanism and culture to ensure the quality and vitality of professional education. In 2006, the Chinese mainland began to build a professional certification system of engineering education that is substantially equivalent to the international system of engineers. In June 2013, China successfully joined the Washington agreement, A mutual recognition agreement for degrees in engineering education, It mean that China's engineering education quality assurance system has won international recognition. The higher education evaluation center of the ministry of education of China has cooperated with shandong university, sun yat-sen university, China agricultural university and south China normal university in the development of accreditation standards for humanities and social sciences majors. In March 2014, the reform document of the ministry of education of China clearly pointed out the direction: out of the 1,200 regular undergraduate institutions of higher learning in China, more 
than 600 will gradually transform into universities based on applied technology, accounting for about $50 \%$ of the total number of universities. Chinese engineering education professional certification association, the 2018 edition engineering education accreditation standards is published, It is the the upgraded version of 2011 and 2015 version, now in the international mainstream countries such as Europe, the United States and China have their own applied undergraduate professional certification standards, But there is no unified global applied undergraduate professional certification standards, certification standard is the main component of higher education quality assurance system. The certification system, the evaluation system, the testing system and the information disclosure system are called the "four systems" for the quality monitoring and evaluation of higher education.

Undergraduate professional certification and the traditional undergraduate evaluation have both connection and difference. This paper compares and explores the standards of Chinese and American engineering professional certification (that is, engineering education major). This paper points out the similarities and differences between the educational certification standards of China and the United States by comparing the relevant indicators of the educational certification standards of China and the United States, in order to provide reference for the improvement of the quality standards of science and engineering education in China and relevant researchers.

\section{RESEARCH STATUS AND TRENDS}

How is the research of applied undergraduate course in China? The database CNKI was searched with the subject Chinese word "applied undergraduate", and 327 articles and books were obtained. If The database was changed with the subject word professional evaluation criteria, and 71 articles were obtained, but no articles were searched with the applied undergraduate professional evaluation criteria. It can be seen that application-oriented undergraduate professional evaluation criteria study is a new field that needs to be studied urgently in China. It is necessary to establish the evaluation standards of engineering education quality suitable for the country's economic and social characteristics. The keyword "Applied undergraduate major" was used to search the English database JOSTOR and 16157 articles and books related Literature information were obtained. From the perspective of the Literature information change trend of JSTOR database, the research area of engineering specialty in the world gradually weakens, which runs counter to the trend that China gradually becomes a research hotspot. On the one hand, this situation in China is related to the rapid development of industrialization and informatization, and on the other hand, it should be related to the promotion of the Chinese education policy reform.Compared with the situation that the research of engineering majors is gradually weakening in U.S.A, the attitude of American applied science and engineering majors towards engineering majors shows a trend of increasing enthusiasm. In 2014, the university of California, Los Angeles, The institute of higher education conducted an annual survey of major choices among American college students in 2014, The proportion of freshmen planned to study science and technology had gradually risen to $45 \%$ by 2014 , In 2007 , The proportion is about 33 percent .An increase in the proportion of freshmen majoring in biological and agricultural sciences and engineering is the main reason for the increase. In 2014, about 14 percent of freshmen planned to major in biological and agricultural sciences ,up from about 9 percent in 2007, and about 14 percent freshmen planned to major in engineering, up from about 8 percent in $2007,10 \%$ plan to major in social and behavioral sciences; 5 percent plan to major in mathematics, statistics or computer science; $3 \%$ plan to major in physical science; That's up from 2011, after more than a decade of declines since the late 1990s in the percentage of freshmen majoring in math, statistics or computer science. Overall, the percentage of science and engineering majors in all racial and ethnic groups has increased since the late 1990s, with the exception of American Indian or Alaskan native groups. In the United States, in the past 20 years, the proportion of researchers in the field of science and engineering is rising year by year, science and engineering doctoral degree in the field of science and engineering doctorate awarded proportion in all disciplines doctoral degree of more and more high, in his doctorate awarded in 2016, Dr Technology accounted for $75 \%$, far higher than $69 \%$ in 2006 and $67 \%$ in 1996 . In The top 10 countries for science and technology PHDS awarded to foreign students, The first place is China, which accounts for more than 90 percent. This also reflects that China attaches more and more importance to science and technology, and this changing trend also reflects the necessity and urgency of engineering certification work in China.

\section{THE INTERNATIONAL COMPARISON OF THE CERTIFICATION STANDARD INDEX SYSTEM OF ENGINEERING MAJOR EDUCATION}

In 2015, the Chinese ministry of education of higher education teaching evaluation center and the national center for public certification of Russian federation signed a memorandum of understanding and sino-russian joint certification of cooperation agreement, It mean a start on international Professional certification by Chinese experts, China's standards, the Chinese model of foreign higher education certification, marked the beginning China model and quality standards to the international stage. In June 2016, China became a full member of the Washington agreement, It is one of the international certification standards for the Engineering speciaty . IEA,the International Engineering Alliance include Dublin agreement, Sydney, the international Engineering professional agreement, international Engineering, APEC Engineering and other Engineering professional certification related agreements, mainland China has only joined the Washington agreement the most popular Engineering professional certification standard system. The Washington agreement is also recognized by the European Network for Accreditation of Engineering Education . On the one hand, China's engineering education must be in line with the evaluation standards of developed countries, on the other hand, With China's rapid development of economy and science and technology, China's engineering education rating standards have also been referenced and 
used by other countries.In the Chinese engineering education there are three ideas :student center, production oriented and continuous improvement, " Also Including The fifth degree " of the engineering professional certification standard system: The achievement degree of training objectives, the adaptability of social needs, the support degree of teachers and conditions, the effectiveness degree of quality assurance operation, the satisfaction degree of students and employer. what is the connection and difference between ABET's engineering certification standards in the Washington agreement and China's engineering education certification standards in 2018 ?

China and America of "engineering certification standards are divided into two parts, general standard and professional standard, Compare the differences between the two countries Engineering education certification standards, The professional classification of the 2017-2018 version of the China certification standard for engineering education is more detailed than that of the 2011 version in China. 2018 version of the China certification standard directory and not specifically listed engineering standards, Some specialties of China 2011 version, such as safety engineering, which do not exist in the United States.But Some College major of U.S. certifications such as Marine engineering, optics and photonics, and nuclear and radiological engineering are not covered by China's certification standards, It may also be due to the initial phase of professional certification, so the profession involved needs to be expanded gradually. But the scope of professional certification in China will certainly expand and should eventually include the vast majority of existing and future engineering specialties.

\subsection{Comparison of the Overall Structure of Chinese and American Engineering Education Certification Standards}

American ABET general certification standards are mainly divided into several parts: general standards for undergraduate professional qualification certification of engineering major, general standards for master's degree certification, and specific professional certification standards. China's certification standards for 2015 and 2018 only have general certification standards for all engineering education majors. Including Student status, graduation requirements for training objectives, continuous improvement, curriculum system, faculty, support conditions, These indicators included in both U.S.and china standards. The relationship between these indicators is that the educational goal is the direction, student cultivation and continuous progress is the process, curriculum is the tool, and teachers, teaching equipment and institution configuration are the guarantee to achieve the educational goal.

not seen the undergraduate-graduate student degree certification in China's certification standards. There is no significant difference between China and the United States in the standards of engineering education certification, One of the indicators of the Chinese standard, supporting conditions, cover two indicators of the American standard, teaching equipment, relevant institutions and leaders.

\subsubsection{Student Development Comparison between Chinese Engineering Education Certification Standards and ABET Standards}

In terms of the expression of student training standards of Chinese engineering education certification standards and ABET standards, there is a small difference between the standards of China and the United States. The certification standards of China and the United States both contain the content of evaluation, supervision and guidance for students to make continuous progress, as well as the recognition of credits for students who transfer to other schools or majors. All contain confirmation of graduation requirements. But China's certification standards include a "system and measures to attract outstanding students," which is a typical Talent selection method with Chinese characteristics. Due to the differences in educational and cultural backgrounds and the different ways of entrance evaluation in western countries, such expressions are generally not found in the texts of evaluation and evaluation.

Joining the Washington agreement marks a historic breakthrough in the development of the connotation of China's engineering education, from a follower of international standards and rules to a participant and maker, and the quality of talent training has gradually been recognized by international authorities. According to the 2016 China engineering education quality report released by the ministry of education, Engineering knowledge, Professional norms, research capabilities, and personal and team relationship management capabilities are all fully up to international standards, but are significantly below international standards in terms of design/development solutions, use of modern tools, communication skills, and project management capabilities. In fact, these abilities are also weaknesses in all segments of Chinese education. In the future education reform, China must pay attention to the improvement of these abilities.

\subsubsection{Comparison of Professional Education Objectives}

Educational objectives refer to the standards to be achieved by the trained personnel. It is the direction and specification of training people. An educational objective is a statement describing the achievements that a college student can achieve over the course of several years of undergraduate study. The education goal is based on the needs of the profession's industry and employers. Both China and the United States have stated educational goals as planned because they both address the needs of employers. In the two countries' accreditation standards, there are no significant differences in educational goals: there are reasonable educational goals that are appropriate for the work of the school organization, and there are written, actionable implementation measures that are regularly reviewed and revised by industry experts. Domestic and international professional certification is mainly evaluated from five dimensions: the attainment of professional training objectives and training effects, the adaptability of professional positioning and social needs, the support of teachers and teaching resources, the effectiveness of quality assurance system operation, and the satisfaction of students 
and employers. Practicality and application are the basic characteristics of engineering majors. The distribution ratio of graduation papers (designs) of Chinese engineering graduates during the 12th five-year plan period was searched. Only from the type of graduation thesis, practical graduation design (thesis) accounts for about $75 \%$, in line with the training objectives of applied engineering education, specific training objectives of each major also need to develop detailed indicators in the certification standards of each major to guide the training practice of professional talent.

\subsubsection{Comparison of Student Achievement Criteria}

Student Achievement means Graduation Requirements, $\mathrm{ABET}$ accreditation standards for engineering education: student achievement must be recorded to enable graduates to achieve planned educational objectives. Student grades describe what students should know and be able to do when they graduate. The knowledge, skills, and behaviors that students acquire through professional learning. The two standard all contain professional level, professional ethics, and norms, innovation ability, team spirit and the team cooperation, management and organization ability, the ability to use modern technology tools, ability to communicate with others, the standard of the two countries' ability to communicate effectively is remarkable, The ability to communicate with others is an important skill from American basic education to higher education. Since the 1990s, the curriculum reform of China's basic education began to focus on cultivating students' communication skills, and the requirement for this ability gradually radiated to the university stage. "Globalization", "sustainable development" and other considerations of overall competence and cognitive level in the standards of both countries meet the basic requirements of modern talent training. On the whole, there is no substantial difference between the standards of the two countries on the graduation requirements of college students, while the requirements of the United States are more general..

\subsubsection{Comparison of Professional Continuous Optimization and Improvement Requirements}

Certification standards should attach importance to the fact that professional development is a dynamic process of continuous improvement, optimization and adjustment, not a static state. Professional curriculum system and evaluation methods should be adjusted dynamically according to the quality changes of cultivated talents. Both national standards for continuous improvement are concerned with the quality control of the teaching process and the evaluation of the achievement of graduation requirements. Both Certification standards indicate that the evaluation results of students can be used as reference for professional continuous improvement. American standard of the quality of teaching mainly through attaches great importance to the evaluation of teaching results (i.e., student achievement), Pay more attention to students' test scores as improving and developing professional references, and the Chinese standard of teaching quality evaluation is mainly measured by graduation requirements, and other indicators, including in addition to performance evaluation which have a broader coverage, and more general, at the same time, the two countries standards also require that the process of professional improving not only On the basis of the student achievement, but also take into account other factors that influence professional improving, for other relevant factors, the China standard are more detailed and specific,It including: graduates tracking feedback, outside the relevant parties to participate in the evaluation of higher education system, analysis on a regular basis education goal realization degree, etc. The core of the two Certification standards is all to evaluate the rationality of the output-oriented curriculum system and the quality of the curriculum. Output-oriented course quality evaluation means that the evaluation should focus on students' learning effectiveness, and the course content, teaching methods and assessment methods must match the graduation requirements supported by the course.

\subsubsection{Curriculum System Comparison}

According to mycos' survey on the social demand and training quality of some universities in 2012, the most needed improvement in the teaching of engineering graduates in 2012 is the lack of internship and practice, accounting for $44 \%$. Among them, 87 percent said their internships were not enough, 21 percent said their course designs were not reasonable and 16 percent said they were not scientific. Under such teaching background, engineering students do not learn much practical skills in university, and it is difficult to compete with others after graduation. The curriculum systems in both countries emphasize the importance of practical teaching, while taking into account the fundamental and important role of basic subjects such as mathematics in engineering. Practice ability is common shotcoming for most China student, but as for students majoring in engineering, hands-on practice ability is the core ability, engineering specialty in colleges and universities should create for students a variety of "solving practical problems", cultivate students' practical ability, Promote students development potential of their own practice through the reasonable evaluation. " mathematics is the key of science, The basic course including mathematical is the foundmental content of students' professional development, the department of the German federal education, science, research and technology' research results show that the modern engineering education is composed of about $30 \%$ of the basic knowledge of mathematics, natural science, $50 \%$ of the engineering science basic knowledge and professional knowledge, and $20 \%$ of interdisciplinary knowledge. From 2011 to 2015 , about $17 \%$ of the credits of Certification courses in engineering education major were science such as mathematics in the United States, and $37-40 \%$ of the credits come from engineering foundation, professional foundation and specialized courses in engineering education major[1]. In other words, mathematics and interdisciplinary knowledge are also indispensable components of engineering education. The overall development of the society requires that the engineering professionals must be able to consider various restrictive factors such as economy, environment, law and ethics when engaged in engineering design. Carnegie Mellon's electrical and computer engineering department 
requires students to take public policy or business courses in addition to core courses. "Students have the freedom to choose their own interests." At the same time, it can increase students' market potential after graduation, said schlesinger, the department's director. In the information age, the "compound" talent with the ability of integration has become the "treasure" sought by enterprises. This requires universities to provide interdisciplinary knowledge, even multi-disciplinary knowledge, In order to train a new generation of engineers. China certification standard clear requirements also that The "General Education courses in The humanities and social sciences credit not less than $15 \%$, American standard, though there is no clear requirement for humanities and social science courses, but puts forward" with engineering and technical content of General Education content (The General Education Component) with professional goals ", compared with Chinese standard requires a little in General Education content.

\subsubsection{Comparison of Faculty Standards}

Teachers' duty is to teach, impart knowledge and solve problems. The faculty is the determinant of the quality of education. Continuous improvement professional certification based on training results requires not only teachers to invest more energy in teaching, Moreover, teachers are required to master the specialized knowledge and skills required for their own and professional sustainable development.Teachers' "diversity of engineering background and engineering experience" is the premise to determine whether students can get practical experience that meets the social needs. If Engineering major existing chaos on professional structure design, the teaching quality is unqualified, the school of engineering education from theory to practice, practice is weak, the existence of the phenomenon such as disconnect between production, The main reason is that there are shortcomings of effective communication channels or channel barriers between university and enterprises, University do not understand the industry demand of choose and employ persons, An engineering university teachers need industry experience, But $80 \%$ to $90 \%$ are highly educated background engineering university teachers has no experience in the industry of intellectuals, the lack of communication and industry with the common language. Teachers power are "software" in engineering university,But it is not seen in the American standard, while the training of teachers in the Chinese standard require that University can effectively support the construction of teachers, attract and stabilize qualified teachers, and support the professional development of teachers themselves, including the guidance and training to young teachers. The level of faculty is one of the core indicators to measure the prospects of a professional development. But American standards require only a higher level of academic excellence: adequate academic authority.

\subsubsection{Comparison of Teaching Equipment Standards}

Classrooms, offices, laboratories, libraries, laboratories, computer and information resources and other related equipment are common elements in the certification standards for teaching equipment in both China and U.S.A. In addition, China standards specifically proposed that "the teaching funds are guaranteed and the total amount can meet the teaching needs." About teaching equipment purchase and maintenance of education funds, the amount of daily teaching funds meet the demand of teaching work, including laboratory equipment maintenance and update fee, embrace experiment, practice and graduation design, etc. the investment of special fund also helps professional continuous improvement, including the educational reform, the laboratory construction, professional activities, academic activities.Both standards regard information resources as a necessary component of teaching equipment, and the importance of information resources in the modern teaching system has been well known. The requirements for information resources in Chinese and American colleges and universities are no longer limited to traditional materials such as previous online literature, but also include online courses based on information technology and other teaching modes, expanding and enriching engineering education means and methods, from which more students benefit. Take iccourse as an example. Among the open courses offered by iccourse, engineering courses account for $22 \%$ of the 899 open video courses, $44 \%$ of the 2,681 open resource-sharing courses, and $31 \%$ of the 213 MOOCs.

\subsubsection{Comparison of Leadership and Supporting Institutions}

Good managers provide effective management and services for teachers and students, and well-trained auxiliary staff maintain and update teaching facilities to ensure the good operation of teaching facilities, which are the basis and guarantee for improving the quality of professional personnel training.Chinese standard stated simply to the requirement of leadership and the supporting agencies in the "Support conditions", and emphasis on university administration of teaching management and service functions, more general expression than American standard, American standard are more specific and clear on the expression of teaching management and auxiliary institutions .such as administrative, financial ,technical personnel ,equipment management, operation are expressed clearly, But the Chinese standards are more specific about the learning environment for students, including facilities for students to practice and innovate., but American standards are relatively general: provide an environment for students to get good grades.

\section{RESEARCH CONCLUSIONS IMPLICATIONS}

\subsection{The Overall Structure of the Engineering Education Certification Standards in China and the United States is Similar}

The framework structure of engineering education certification standards in China and the United States is 
similar, including general certification standards and professional certification standards. The certification standards of engineering education in both countries include such indicators as students, education objectives, graduation requirements, continuous improvement, curriculum system, faculty, and support conditions, and most of the principal indicators are the same or similar. Gradual convergence of educational standards in various countries is a basic feature under the background of education globalization, It is also an inevitable corollary as the trend of close educational exchanges between China and the United States. With the continuous improvement of the internationalization degree of Chinese education, there will be more similarities between the certification standards of various disciplines in China and the United States, including the certification standards of engineering education. The certification standards of science and engineering majors may eventually move towards the international unified standards.

\subsection{The Paper Emphasizes Teaching Practice is the Common Feature of the Chinese and American Engineering Education Certification Standards}

Both China and the United States emphasize the importance of practice in engineering education and emphasize that teaching practicality is the core factor of science and engineering application-oriented professional certification. To cultivate application-oriented talents, the construction of the teaching system reflects the word "application", and the core of application is practical teaching. In 327 Chinese literature, The keywords co-occurrence frequency highly with applied undergraduate professional are course system, teaching, practice teaching, subject construction, $\mathrm{I}$ is consistent with requirements of the indicators of the China 2018 edition of "engineering education professional certification standards", the standard includes several indicators: training target, course system, teaching staff, continuous improvement, including curriculum system Settings and curriculum quality evaluation, which contains the discipline construction, curriculum setting, teaching reform and the basic requirement of the practice teaching, "application technology university (college) alliance" seted up in 2013 is put forward that the specialty construction, curriculum setting and teaching process of application-oriented undergraduate major need exploratory, research-oriented and theoretical. The results of talent training and basic research need high-end, diversified and innovative. effective, timely and advantageous are characteristics of in serving the society and applying research. What are the main problems in engineering education in China? In November 2014, the higher education teaching evaluation center of the ministry of education released the quality report of engineering education in China of 2013 : the employer believes that the practical ability of Chinese engineering graduates needs to be strengthened; Industry groups say Chinese engineering graduates need to improve their ability to compete internationally, among other things. Some universities in China have only superficial knowledge of the training mode of application-oriented talents and the important knowledge of strengthening practical teaching. Even in the concept of understanding, but often in the conditions, environment, foundation and other factors, wait and see, wait, perfunctory phenomenon has a certain degree of universality. Objective problems mainly include the shortage of multimedia teaching facilities and the traditional teaching mode of "one piece of chalk, one book". Lack of training simulation field, the existing training facilities fail to meet the needs of teaching practice, off-campus practice base construction is weak, there is a widespread floating practice base in the form of questions, on the one hand, due to the current our country enterprise restructuring after managers tend to maximize the pursuit of short-term interests, on the other hand can also be attributed to the investment of funds in the sector, the manpower shortage. We should increase the necessary financial investment in practical teaching. The teaching reform and even the adoption of international professional certification by referring to the certification standards of science and engineering applied majors in the international mainstream countries will help to control the scientific and reasonable teaching standards. At the same time, as the cultivation of talents in the field of engineering and manufacturing, teachers should first understand the standards of talent demand in the industry. The introduction of teachers should consider teachers with practical experience, and also urge teachers to combine teaching and practice, so as to improve the degree of conformity between talent training and social needs.

\subsection{Both Standards Attach Importance to the Supporting Role of Basic Disciplines in the Quality of Engineering Education}

In order to support professional development, Both the two Certification standards of China and U.S. attaches great importance to basic subjects such as mathematics, physics, Einstein said: "mathematics is the key to the natural sciences, It is well known that mathematics,physics and other subjects are basic role of engineering education, mathematics itself include many Applied major, for example, computational mathematics, including: the numerical approximation and computational geometry, matrix calculation, artificial neural network and its learning algorithm, numerical nonlinear analysis and its application in the inverse problem and financial. Applied mathematics includes: applied differential equations, fluid computation and simulation, dynamical systems theory and applications, graphics and image processing, approximation theory and its applications, coding and cryptography, machine learning and deep learning theory and algorithms. There are also highly applied probability statistics and other majors, which are widely used in data processing of natural science and social science. and the tool function of mathematics for engineering education major should not be underestimated. Therefore, the importance of the above basic disciplines is emphasized in the engineering education certification standards of China and the United States. 
evaluation standard research in international comparison horizon,"No.B - a / 2016/01/04.

\section{the Key Points in the Construction of Application-oriented Undergraduate Majors Including Engineering}

4.4. Quality and Connotation Construction are

In 2016, the ministry of education of the China Surveyed thatmechanical engineering society, China petroleum and chemical industry association, China water resources institute, China computer society, China software industry association, China electrotechnical society six industry group, according to the research results, Chinese engineering education basic meet the needs of the rapid development of the industry, Industry engineering technical personnel meet the basic demand of society. However, engineering graduates need to be further improved in such aspects as international competitiveness, management ability and interdisciplinary knowledge integration ability. The connotation and supporting elements of quality need to be truly implemented. implement is the "last kilometer" of quality construction. and there is much room for continuous improvement in such connotation elements as engineering education concept, classroom teaching, supporting conditions, teacher team construction and students' ability development. In terms of top-level design and dynamic adjustment, the top-level strategic design of engineering education fails to match the "2025" goal, and the connection between talent training chain, national innovation chain and industrial chain needs need to be strengthened. Professional dynamic adjustment mechanism needs to be improved; The breadth and depth of cooperative education between industry and university need to be strengthened urgently. At the beginning of 2018, the ministry of education of China released the national standards on the teaching quality of undergraduate majors in ordinary Colleges and universities, which covers all undergraduate majors, covers major aspects and key links of specialty construction and talent cultivation. For example, the national standards for the teaching quality of pharmaceutical specialty includes eight parts, including the overview of the specialty, the training objectives, the training specifications, the faculty, the teaching conditions, the student development, the quality assurance system and the appendix. In the appendix, it is also adjusted according to the characteristics of the major. For example, pharmacy and pharmaceutical engineering majors give Suggestions on the curriculum system, and clinical pharmacy majors give practical teaching base standards. According to the characteristics of the discipline, Each relevant discipline and major can, according to the characteristics of this discipline, refine rules and specify operational rules in each link of the teaching process, forming a collaborative operation talent training structure of "certification" + "teaching evaluation".

\section{ACKNOWLEDGMENT}

This article is in the Teaching research for the ministry of education humanities and social science plan project in 2017: "The international comparative study of applied science and engineering professional evaluation standards of applied undergraduate colleges and universities"No.17 yja880070, and,JiangSu province education planning key projects " applied undergraduate colleges and universities of science and engineering applied professional construction and

\section{REFERENCES}

[1] The History of ABET.http://www. abet.org/history.shtml. [2] 2008 Accreditation Statistics.http:// www.abet.org/statistics.shtml.
[3]
Washington
Accord.http://www.

washingtonaccord.org/Washington.

[4] The Members of ABET.http://www. abet.org/gov.shtml.

[5] The ABET Governance

Documents.http://www.abet.org/const itution.shtml.

[6] Accreditation Policy and Procedure Manual. http://www.abet.org/ forms.shtml.

[7] Deadlines and Due Dates.http://www. abet.org/deadline.shtml.

[8] Standards of Conduct.http://www. abet.org./code.shtml.

[9] International Activities.http://www. abet.org/global.shtml.

[10] Ministry of education higher education teaching evaluation center. China engineering education quality report .http://www.jyb.cn/info/jytjk/_656794.html $2016=04-08 /$.

[11] Is engineering education ready for made in China 2025?http://edu.people.com.cn/n1/2017/

1016/c367001-29588555.html. 